\title{
Ympärivuotisen kasvihuonevihannestuotannon tehostaminen
}

Juha Näkkilä, Tiina Hovi-Pekkanen ja Risto Tahvonen

MTT Kasvintuotannon tutkimus, puutarhatuotanto, Toivonlinnantie 518, 21500 Piikkiö, juha.nakkila@mtt.fi

\section{Tiivistelmä}

Vuosina 2001-2005 Maa- ja elintarviketalouden tutkimuskeskuksessa (MTT) on kehitetty oloihimme soveltuvaa ympärivuotista tuotantotekniikkaa kurkulle, tomaatille ja paprikalle. Tutkimusta ovat rahoittaneet MTT:n ja Maa- ja metsätalousministeriön lisäksi mm. Kauppapuutarhaliitto, Kekkilä Oyj ja Oy Schetelig Ab. Tutkimushankkeessa on tutkittu mm. korkean vihanneskasvuston valo-olojen tasoittamista kasvuston alaosaa valottamalla. Tavoitteena oli kehittää valotusmenetelmä, jolla tehostetaan tuotannon energiatehokkuutta vihannesten laadusta tinkimättä.

Nykyisin yhä suureneva osuus kasvihuonetuotannosta on ympärivuotista, sillä uutta viljelypinta-alaa rakennetaan nykyisessä markkinatilanteessa vain lähinnä ympärivuotista tuotantoa varten. Ympärivuotisessa tuotannossa vuotuinen sato on 2-3 kertaa suurempi kuin noin kahdeksan tuotantokuukautta kestävässä luonnonvaloon perustuvassa tuotannossa. Ympärivuotinen tuotanto perustuu tekovalon tehokkaaseen käyttöön auringon valon lisänä.

Kasveja valotettiin suurpainenatrium-valaisimilla $16-20 \mathrm{~h} \mathrm{vrk}^{-1}$, kun kokonaissäteily alitti 214$286 \mathrm{~W} \mathrm{~m}^{-2}$. Kasvihuoneen hiilidioksidipitoisuus nostettiin 800-1000 $\mu 1 \mathrm{l}^{-1}$ tasolle, kun tuuletusluukut olivat riittävän kiinni. Valotussähkön energiankäyttötehokkuutta voitiin nostaa vuoden ajasta riippuen 5-30 \%, kun osa kasvuston yläpuolisista valaisimista sijoitettiin riviväliin valaisemaan lehtiä kasvuston alaosassa. Tulosten perusteella kasvuston alaosan valaisuun käytetystä pystysuoraan sijoitetusta polttimosta säteily kohdistuu tehokkaasti kasviriviin ja sitä hukkaantuu varsin vähän alas käytävälle ja ylös. Kasvuston alaosan valotuksessa havaittuja kasteluun liittyviä kesäajan laatuongelmia voidaan todennäköisesti vähentää tasoittamalla kasvirivin suuntaista valotusta pienitehoisemmilla valaisimilla ja tähän tarkoitukseen kehitetyllä heijastimella. Kasvuston alaosaa valottavien valaisimien tuotekehitys on kuitenkin vasta alkanut.

Niukan luonnon valon aikainen tuotanto aletaan hallita jo niin hyvin, että satoa saadaan talvella lähes yhtä paljon kuin kesällä. Kurkkusato voi olla kesällä jopa heikompi kuin talvella, koska kasvihuoneen olosuhteita ei hallita yhtä hyvin kesällä korkean ulkolämpötilan takia. Kun kasvihuoneen lämpötilaa, ilmankosteutta ja hiilidioksidipitoisuutta opitaan hallitsemaan täsmällisesti ja taloudellisesti ympäri vuoden, voidaan nykyisiä satoja lisätä vielä merkittävästi. 


\section{Johdanto}

Riittävä yhteyttämisvalo, hiilidioksidi ja vesi ovat kasvihuonetuotannon perusedellytyksiä. Kasvihuoneiden ympärivuotinen tuotanto perustuu Suomessa tekovalon käyttöön auringon valon lisänä. Kasveja valotetaan niukan luonnon valon aikaan 12-20 tuntia vuorokaudessa suurpainenatriumvalaisimilla. Kasvihuoneilman hiilidioksidipitoisuutta nostetaan tavanomaisesta $350 \mu \mathrm{ll}^{-1}$ tasosta esimerkiksi 600-1000 $\mu 1 \mathrm{l}^{-}$tasolle, jotta kasvit yhteyttäisivät mahdollisimman tehokkaasti niukassa valossa.

Puutarhayritysrekisterin mukaan $200326 \%$ kurkun, $12 \%$ tomaatin ja $8 \%$ paprikan viljelyalasta oli tekovalotettua. Tekovalotetun tuotannon osuus on tästä edelleen kasvanut, sillä kesäajan markkinahäiriöt, jotka aiheutuvat kesän runsaasta tuotannosta ja alhaisista tuotehinnoista, saavat viljelijät hakemaan tuloja yhä useammin luonnonvaloviljelykauden ulkopuolelta. Tekovalotukseen käytetyn sähkön osuus tuotantokustannuksista on kurkulla noin yksi kolmasosa ja tomaatilla noin yksi neljäsosa. Viljelijä on harkittava tarkkaan, miten tekovalotuksesta saadaan paras tuotto nykyisillä sähkön hinnoilla.

Kurkkua, tomaattia ja paprikaa viljellään useita metrejä korkeissa kasvustoissa. Korkeassa kasvustossa kaikki lehdet eivät yhteytä tehokkaasti valon puutteen vuoksi (Hovi 2001). Kasvihuonevalaisimet asennetaan yleensä kasvirivien väliin kasvien yläpuolelle, jolloin kasvin yläosan lehdet saavat runsaasti valoa, mutta kasvin alaosan lehdille valoa tulee niukasti. Yhdysvalloissa Rodriguez ja Lambeth (1975) sekä Norjassa Grimstad (1987) tutkivat tomaattikasvuston alaosan valotuksen vaikutuksia hyvin tuloksin, mutta menetelmä ei kuitenkaan yleistynyt käytäntöön. Kokeissa käytettiin loisteputkivalaisimia, jotka eivät yleistyneet kasvihuoneviljelyssä. Vuonna 2001 MTT puutarhatuotannossa alkoi tutkimushanke, jossa tutkittiin kasvuston valo-olojen tasoittamisen vaikutuksia satoon ja sen laatuun kasvuston alaosaa valottamalla.

\section{Lehden iän vaikutus yhteyttämiseen}

Kurkun eri ikäisten lehtien yhteyttämistä mitattiin, kun fotosynteettisesti aktiivista säteilyä oli 160-170 $\mu \mathrm{mol} \mathrm{m} \mathrm{m}^{-2} \mathrm{~s}^{-1}$. Säteily vastasi tekovaloviljelyssä tavanomaista tasoa. Yhteyttämismittausten perusteella viisi viikkoa vanha kurkun lehti pystyi yhteyttämään yhtä hyvin kuin nuori lehti, kunhan vanha lehti sai yhtä paljon valoa kuin nuori lehti (Hovi, 2002). Kun kaikille lehdille pystyttiin tarjoamaan yhtä paljon valoa, kasvin satokertymä oli sitä suurempi, mitä enemmän kasvissa oli lehtiä (Hovi, 2003). Kasvin lehtien määrän kaksinkertaistuessa 20 lehdestä 40 lehteen sadon määrä kasvoi $29 \%$. Sadonlisä saatiin hedelmien lukumäärän lisääntymisenä ja painavampina hedelminä. Kasvin juuristo oli kasvustoa raivattaessa sitä runsaampi, mitä enemmän kasvilla oli hyvin valoa saavia lehtiä. Yhteyttämismittauksin todettiin, että nuoret ja vanhat lehdet yhteyttivät samaan tapaan kurkulla yleisesti käytetyn 20 tunnin valojakson ajan.

Tekovaloviljelyssä käytetyssä alaslaskumenetelmässä kurkun lehti yleensä poistetaan 3-4 viikon ikäisenä. Saatujen tulosten perusteella alalehtien poistamisella ei ole kiirettä, jos alalehtien valonsaantia voidaan parantaa, sillä sato kasvoi yhteyttävien lehtien lukumäärän lisääntyessä. On vain kehitettävä keino, jolla tasoittaa valoisuutta kasvuston ylä- ja alaosan välillä.

\section{Kasvuston alaosan valotuksen vaikutus sadon määrään}

Ensimmäiset lupaavat tulokset kasvuston alaosan valottamisesta saatiin talvella 2001-2002 (Hovi ym., 2004). Tavanomaista valotustapaa, jossa kaikki valaisimet on sijoitettu kasvuston yläpuolelle, verrattiin tapaan, jossa osa valaisimista sijoitettiin alemmas kasvuston riviväleihin. Kurkkukasvuston alalehtien valoisuutta lisättiin siirtämällä valaisinten asennustehosta $\left(170 \mathrm{~W} \mathrm{~m}^{-2}\right) 25 \%$ valaisemaan alalehtiä. Alalehtiä valaisevat alavalot olivat 400 watin valaisimia, joiden polttimo roikkui pystysuorassa asennossa 1,3 metrin korkeudella maasta. Alavaloista käytetään myös nimitystä rivivälivalo ja välivalo. Kasvuston yläpuoliset valaisimet sammuivat, kun kokonaissäteily ylitti $286 \mathrm{~W}$ $\mathrm{m}^{-2}$, mutta alavalot olivat päällä koko 20 tunnin valojakson ajan. Alavalojen ansiosta kurkun kokonaissatoa kertyi vuodessa yhteensä $139 \mathrm{~kg} \mathrm{~m}^{-2}$, kun tavanomaisella valotuksella satoa saatiin 120 $\mathrm{kg} \mathrm{m}^{-2}$ (taulukko 1) Alavalo lisäsi kurkkusatoa vuoden aikana $16 \%$ tavanomaiseen valotustapaan verrattuna; talvella saatiin $15 \%$, keväällä $24 \%$ ja kesällä $5 \%$ enemmän satoa. Alavalon sadonlisä saatiin hedelmien lukumäärän ja painon kasvuna. Alavaloista säteili valtaosa valosta ja lämmöstä vapaasti kasvirivien suuntaan, joten valaisimien valo- ja lämpövaikutus oli epätasainen kasvirivin 
suunnassa. Tämä vaikeutti kasvien kastelua varsinkin kesäaikaan. Tämän koejakson aikana havaittiin, että kesällä runsaan luonnonvalon aikaan ensimmäisen luokan kurkun viikkosato oli alempi kuin niukemman luonnonvalon aikaan talvella ja keväällä.

Taulukko 1. Valotustavan vaikutus kurkun satoon, ensimmäisen luokan hedelmän keskipainoon ja viikkosatoon sekä valotuksessa käytetyn energian käytön tehokkuuteen. Energiankäytön tehokkuus laskettiin kokonaissatona käytettyä kilowattituntia kohden.

\begin{tabular}{|c|c|c|c|c|c|c|c|}
\hline Kasvusto & Valotustapa & $\begin{array}{l}\text { Koko } \\
\text { sato } \\
\left(\mathrm{kg} \mathrm{m}^{-2}\right)\end{array}$ & $\begin{array}{c}\text { Koko } \\
\text { sato } \\
\left(\mathrm{kpl} \mathrm{m}^{-2}\right)\end{array}$ & $\begin{array}{c}\text { 1. lk. } \\
\text { sato } \\
\left(\mathrm{kg} \mathrm{m}^{-2}\right)\end{array}$ & $\begin{array}{c}\text { 1. lk. } \\
\text { hedelmän } \\
\text { keskipaino } \\
\left(\mathrm{g} \mathrm{kpl}^{-2}\right)\end{array}$ & $\begin{array}{c}\text { 1. lk. } \\
\text { viikkosato } \\
\left(\mathrm{kg} \mathrm{m}^{-2} \text { viikko }^{-1}\right)\end{array}$ & $\begin{array}{l}\text { Energian } \\
\text { käytön } \\
\text { tehokkuus } \\
\left(\mathrm{g} \mathrm{kWh}^{-1}\right)\end{array}$ \\
\hline \multirow[t]{3}{*}{ Talvi } & Tavanomainen & 34,8 & 99,7 & 32,0 & 321 & 2,7 & 95,6 \\
\hline & Alavaloa $25 \%$ & 40,2 & 113,0 & 38,2 & 338 & 3,2 & 110,4 \\
\hline & Merkitsevyys & * & * & * & ** & * & * \\
\hline \multirow[t]{3}{*}{ Kevät } & Tavanomainen & 47,1 & 137,5 & 42,1 & 347 & 2,9 & 134,2 \\
\hline & Alavaloa $25 \%$ & 58,5 & 158,3 & 55,4 & 373 & 3,9 & 156,4 \\
\hline & Merkitsevyys & $* *$ & * & $* *$ & ** & ** & ** \\
\hline \multirow[t]{3}{*}{ Kesä } & Tavanomainen & 37,9 & 111,8 & 30,8 & 354 & 2,3 & 146,9 \\
\hline & Alavaloa $25 \%$ & 39,9 & 115,7 & 32,1 & 353 & 2,4 & 134,8 \\
\hline & Merkitsevyys & * & * & & & & \\
\hline \multirow[t]{3}{*}{ Yhteensä } & Tavanomainen & 119,8 & 359,1 & 104,8 & 340 & 2,6 & 123,1 \\
\hline & Alavaloa $25 \%$ & 138,6 & 394,2 & 125,7 & 359 & 3,2 & 134,2 \\
\hline & Merkitsevyys & $* * *$ & ** & ** & ** & ** & ** \\
\hline
\end{tabular}

Viljelykaudella 2003-2004 400 watin alavalaisimet korvattiin 250 watin alavaloilla (Hovi, 2004). Rivin suuntaiset valoisuuserot tasoittuivat, kun alavalaisimien lukumäärää lisättiin ja valaisimissa käytettiin heijastinta. Tavanomaisessa valotuksessa asennusteho $170 \mathrm{~W} \mathrm{~m}^{-2}$ säilyi ennallaan, mutta alavaloja käytettäessä asennusteho jäi hieman pienemmäksi $\left(163 \mathrm{~W} \mathrm{~m}^{-2}\right)$. Kasvuston yläpuoliset valaisimet sammuivat, kun kokonaissäteily ylitti $286 \mathrm{~W} \mathrm{~m}^{-2}$ ja alavalot sammuivat, kun kokonaissäteily ylitti $571 \mathrm{~W} \mathrm{~m}^{-2}$. Kun alavalojen osuus valaisinten asennustehosta oli 24 tai $48 \%$, kurkkusatoa kertyi vuodessa 117 tai $118 \mathrm{~kg} \mathrm{~m}^{-2}$ ja tavanomaisesta valotuksesta $108 \mathrm{~kg} \mathrm{~m}^{-2}$. Alavalo lisäsi kokonaissatoa vuoden aikana 8 tai $9 \%$ tavanomaiseen valotukseen nähden, mutta alavalon osuuden kasvattaminen $24 \%$ :sta $48 \%$ :iin ei enää merkittävästi lisännyt tuotantoa. Alavalon sadonlisä saatiin etupäässä hedelmien painon nousuna.

Uutta valotustapaa on tutkittu myös paprikalla ja tomaatilla. Suurpainenatriumvalaisinten asennusteho $170 \mathrm{~W} \mathrm{~m}^{-2}$ oli kaikilla koejäsenillä sama. Alavalojen osuus asennustehosta oli $50 \%$. Tekovaloa annettiin 400 watin polttimoilla. Paprikalle tekovaloa annettiin enintään 16 ja tomaatille 18 $\mathrm{h} \mathrm{vrk}^{-1}$. Valaisimet sammuivat, kun kokonaissäteily kasvihuoneen ulkopuolella ylitti 214-286 $\mathrm{W} \mathrm{m}^{-2}$.

Paprika istutettiin 11.11.2003 ja raivattiin 1.11.2004 40 sadonkorjuuviikon jälkeen Alavalo lisäsi paprikan kokonaissatoa keskimäärin $23 \%$ ja ensimmäisen luokan satoa $15 \%$ tavanomaiseen valotukseen verrattuna (taulukko 2) (Hovi ja Hellstén, 2003). Alavalo lisäsi hedelmien lukumäärää 18 $\%$ ja nosti hieman hedelmän keskipainoa. Alavaloista saatavan hyödyn kannalta satokausi jakaantui kahteen osaan. Juhannukseen asti paprika hyötyi selvästi alavalosta, mutta tämän jälkeen satoa saatiin kummastakin valotustavasta yhtä paljon. Kesäkuussa 21 satoviikon jälkeen paprikan satokertymä oli alavalossa vielä yli $40 \%$ korkeampi kuin tavanomaisen valotustavan. Vuonna 2003 tehdyssä esikokeessa tulos oli samankaltainen. 
Taulukko 2. Valotustavan vaikutus paprikan satoon, ensimmäisen luokan hedelmän keskipainoon ja viikkosatoon sekä valotuksessa käytetyn energian käytön tehokkuuteen. Energiankäytön tehokkuus laskettiin kokonaissatona käytettyä kilowattituntia kohden.

\begin{tabular}{lrrrrrr}
\hline Valotustapa & $\begin{array}{c}\text { Koko } \\
\text { sato } \\
\left(\mathrm{kg} \mathrm{m}^{-2}\right)\end{array}$ & $\begin{array}{c}\text { Koko } \\
\text { sato } \\
\left(\mathrm{kpl} \mathrm{m}^{-2}\right)\end{array}$ & $\begin{array}{c}\text { 1. lk. } \\
\text { sato } \\
\left(\mathrm{kg} \mathrm{m}^{-2}\right)\end{array}$ & $\begin{array}{c}\text { 1. lk. } \\
\text { hedelmän } \\
\text { keskipaino } \\
\left(\mathrm{g} \mathrm{kpl}^{-1}\right)\end{array}$ & $\begin{array}{c}\text { 1. lk. } \\
\text { vilkkosato } \\
\left(\mathrm{kg} \mathrm{m}^{-2} \text { viikko }\right.\end{array}$ & $\begin{array}{c}\text { Energian } \\
\text { käytön } \\
\text { tehokkuus } \\
\left(\mathrm{g} \mathrm{kWh}^{-1}\right)\end{array}$ \\
\hline Tavanomainen & 20,1 & 142,5 & 15,9 & 151 & 0,4 & 33,9 \\
Alavaloa 50 \% & 24,7 & 167,8 & 19,0 & 156 & 0,5 & 41,2 \\
Merkitsevyys & $*$ & $*$ & $*$ & $*$ & $*$ & $*$ \\
\hline
\end{tabular}

Tomaatin kevätkasvusto istutettiin 29.-30.11.2004 ja raivattiin 3.3.2005 runsaan 13 sadonkorjuuviikon jälkeen. Kesäkasvusto istutettiin 7.4.2005 ja raivattiin 3.10.2005 runsaan 18 sadonkorjuuviikon jälkeen. Alavalo kasvatti tomaatin kokonaissatoa keväällä keskimäärin $30 \%$ ja kesällä $8 \%$ verrattuna tavanomaiseen valotukseen (taulukko 3) (Näkkilä ja Muranen, 2005). Alavalo lisäsi hedelmien lukumäärää keväällä ja kesällä sekä nosti hedelmien keskipainoa keväällä. Vuoden 2003 esikokeissa alavalo lisäsi tomaatin satoa vuodenajasta riippuen keskimäärin 6-23\% tavanomaiseen valotukseen verrattuna.

Taulukko 3. Valotustavan vaikutus tomaatin satoon, ensimmäisen luokan hedelmän keskipainoon ja viikkosatoon sekä valotuksessa käytetyn energian käytön tehokkuuteen. Energiankäytön tehokkuus laskettiin kokonaissatona käytettyä kilowattituntia kohden.

\begin{tabular}{|c|c|c|c|c|c|c|c|}
\hline Kasvusto & Valotustapa & $\begin{array}{l}\text { Koko } \\
\text { sato } \\
\left(\mathrm{kg} \mathrm{m}^{-2}\right)\end{array}$ & $\begin{array}{c}\text { Koko } \\
\text { sato } \\
\left(\mathrm{kpl} \mathrm{m}^{-2}\right)\end{array}$ & $\begin{array}{c}\text { 1. lk. } \\
\text { sato } \\
\left(\mathrm{kg} \mathrm{m}^{-2}\right)\end{array}$ & $\begin{array}{c}\text { 1. lk. } \\
\text { hedelmän } \\
\text { keskipaino } \\
\left(\mathrm{g} \mathrm{kpl}^{-1}\right)\end{array}$ & $\begin{array}{c}\text { 1. lk. } \\
\text { viikkosato } \\
\left(\mathrm{kg} \mathrm{m}^{-2} \text { viikko }{ }^{-1}\right)\end{array}$ & $\begin{array}{l}\text { Energian } \\
\text { käytön } \\
\text { tehokkuus } \\
\left(\mathrm{g} \mathrm{kWh}^{-1}\right) \\
\end{array}$ \\
\hline \multirow[t]{3}{*}{ Kevät } & Tavanomainen & 20,5 & 304,6 & 18,5 & 72 & 1,4 & 57,1 \\
\hline & Alavaloa $50 \%$ & 26,6 & 368,0 & 23,8 & 78 & 1,8 & 73,8 \\
\hline & Merkitsevyys & ** & ** & * & * & * & ** \\
\hline \multirow[t]{3}{*}{ Kesä } & Tavanomainen & 31,8 & 435,7 & 27,8 & 75 & 1,5 & 114,9 \\
\hline & Alavaloa $50 \%$ & 34,5 & 467,0 & 29,8 & 76 & 1,6 & 117,2 \\
\hline & Merkitsevyys & * & * & & & & \\
\hline
\end{tabular}

\section{Kasvuston alaosan valotuksen vaikutus sadon laatuun}

Kasvuston alaosan valotus paransi kurkkusadon ulkoista laatua kasvattamalla ensimmäisen luokan sadon osuutta. Alavalo lisäsi hedelmän kuoren lehtivihreäpitoisuutta, joten alavalossa hedelmät olivat vihreämpiä kuin tavanomaisessa valotuksessa. Alavalon käyttö paransi hieman hedelmien säilyvyyttä, mutta muutos oli niin pieni, ettei sillä ole välttämättä käytännön merkitystä. Varastointikokeessa havaittiin, että eri tavalla valotetut kurkut pilaantuivat varastoinnin aikana eri tavalla. Tavanomaisesti valotetut kurkut todettiin kauppakelvottomiksi yleensä hedelmän kellastumisen takia. Alavalon osuuden kasvaessa kellastuneiden hedelmien osuus pieneni ja kaulastaan nahistuneiden hedelmien osuus suureni.

Valotustavalla ei ollut vaikutusta ensimmäisen luokan sadon osuuteen paprikalla tai tomaatilla. Tomaatin kesäkasvustosta todettiin, että valotustavalla ei ollut vaikutusta hedelmän kuivaainepitoisuuteen eikä liukoisen kuiva-aineen pitoisuuteen (brix-luku). Kasvuston alaosan valotuksella oli kesäaikaan epäedullisia vaikutuksia paprika- ja tomaattisadon ulkoiseen laatuun. Alavalo lisäsi paprikalla latvamätää ja tomaatilla hedelmien lievää korkkiutumaa. Hedelmien latvamätä ja 
korkkiutuma johtuvat kastelun ja kasvin vedenoton epätasapainosta. Mittausten mukaan alhaalla olevat valaisimet lämmittivät ilmaa lehtien läheisyydessä ja alensivat ilman suhteellista kosteutta. Käytännössä tämä lisää kasvin haihdutusta ja vedenkulutusta.

\section{Kasvuston alaosan valotuksen vaikutus valotusenergian käytön tehokkuuteen}

Valotuksen sähköenergian käytön tehokkuutta mitattiin jakamalla sadon paino valotukseen käytetyllä energiamäärällä. Vuoden aikana alavalo tuotti $9 \%$ (viljelykausi 2001-2002) tai 6-8 \% (viljelykausi 2003-2004) enemmän kurkkusatoa kilowattituntia kohti kuin tavanomainen valotus. Talvella ja keväällä alavalon tehokkuus oli suurempi kuin tavanomaisen valotustavan kumpanakin viljelykautena. Ensimmäisenä viljelykautena alavalon tehokkuus jäi kesällä alle tavanomaisen viljelyn tehokkuuden, mutta toisena viljelykautena alavalon energian käyttö tehostui jo lähes tavanomaisen viljelyn tasolle. Tehostuminen johtui ainakin osittain valotuksen vähenemisestä. Alavalo lisäsi paprikalla sähköenergian käytön tehokkuutta $23 \%$ tavanomaiseen valotukseen verrattuna. Tomaatilla alavalo tehosti keväällä sähköenergian käytön tehokkuutta $29 \%$ tavanomaiseen valotusmenetelmään verrattuna, mutta kesällä valotustavan vaikutus sähköenergian käytön tehokkuuteen oli pieni.

\section{Johtopäätökset}

Kurkun, paprikan ja tomaatin tulokset valotustavan vaikutuksesta eri vuodenaikoina olivat samansuuntaisia. Alavalo lisäsi satoa ja paransi energian käytön tehokkuutta vähäisen luonnonvalon aikaan talvella ja keväällä. Kesällä valotustavan vaikutus satoon ja sähköenergian käytön tehokkuuteen jäi vähäiseksi. Kesän runsas luonnon valo vähensi tekovalon käyttötunteja ja lisäsi kasvihuoneen tuuletustarvetta. Runsas tuuletus yleensä myös katkaisi hiilidioksidilannoituksen. Tuuletuksen ja kasvuston yhteyttämisen takia ilman hiilidioksidipitoisuus laski nopeasti. Alhaisen hiilidioksidipitoisuuden ja vähäisen tekovalotuksen takia valotustavan vaikutus satoon ja energian käytön tehokkuuteen jäi pieneksi. Kesällä ei ole tehokasta käyttää alavaloa huomattavasti pitempään kuin tavanomaisia valaisimia. Alavalon käyttö tehostui, kun alavalojen ja tavanomaisten valaisimien käyttöajat olivat lähes samat.

Kesällä viljelijän kannattaa käyttää mieluummin alavaloja kuin kasvuston yläpuolisia valaisimia, koska luonnon valoa saadaan runsaasti kasvuston yläosaan, muttei välttämättä kasvuston alaosaan. Tekovalon käyttö kannattaa kuitenkin rajata sellaiseen aikaan, jolloin kasvihuoneen hiilidioksiditaso on hallittavissa.

Kokeissa havaittiin, että kasvuston alaosan valaisuun käytetystä pystysuorasta polttimosta säteily kohdistuu tehokkaasti kasviriviin ja sitä hukkaantuu varsin vähän alas käytävälle ja ylös. Kasvuston alaosan valotuksessa havaittuja kasteluun liittyviä kesäajan laatuongelmia voidaan todennäköisesti vähentää tasoittamalla kasvirivin suuntaista valotusta pienitehoisemmilla valaisimilla ja tähän tarkoitukseen kehitetyllä heijastimella. Kasvuston alaosaa valottavien valaisimien tuotekehitys on kuitenkin vasta alkanut.

Kasvuston alaosan valoisuutta voidaan parantaa myös esimerkiksi lisäämällä valaisinten asennustehoa tai valitsemalla sellainen valaisin, jonka heijastin soveltuu korkean kasvuston valaisuun. Asennustehon kasvattamista kannattaa harkita tarkkaan, sillä suurempi teho lisää valaisimien lämmittävää vaikutusta ja kasvihuoneen tuuletustarvetta. Kauppapuutarhaliiton tekemien mittausten mukaan myös valaisimen asennussuunta vaikuttaa valon jakautumiseen kasvustossa (Murmann, 2005).

Niukan luonnon valon aikainen tuotanto aletaan hallita jo niin hyvin, että satoa saadaan talvella lähes yhtä paljon kuin kesällä. Kurkkusato voi olla kesällä jopa heikompi kuin talvella, koska kasvihuoneen olosuhteita ei korkean ulkolämpötilan takia pystytä hallitsemaan kesällä yhtä hyvin. Kun kasvihuoneen lämpötilaa, ilmankosteutta ja hiilidioksidipitoisuutta opitaan hallitsemaan täsmällisesti ja taloudellisesti ympäri vuoden, voidaan nykyisiä satoja lisätä vielä merkittävästi.

\section{Kirjallisuus:}

Grimstad, S.0.1987. Supplementary lighting of early tomatoes after planting out in glass and acrylic greenhouses. Scientia Horticulturae 33: 189-196.

Hovi, T. 2001. Lisää valoa kurkun alalehdille. Puutarha \& kauppa 4: 41, 14-15.

Hovi, T. 2002. Kyllä se vanhakin jaksaa. Puutarha \& kauppa 5: 20, 8-9.

Hovi, T. 2003. Hyvin valoa saavat lehdet turvaavat kurkkusadon. Puutarha \& kauppa 6:38, 4-5.

Hovi, T. 2004. Alavaloilla enemmän ja parempia kurkkuja. Puutarha \& kauppa 7:39, 14-15. 
Hovi, T., Näkkilä, J. ja Tahvonen, R. 2004. Interlighting improves production of year-round cucumber. Scientia Horticulturae 102:3, 238-294.

Hovi, T ja Hellstén, E. 2005. Alavalo sopii paprikalle. Puutarha \& kauppa 8:15, 14-15.

Murmann, T. 2005. Valitse valaisin viisaasti. Puutarha \& kauppa 8: 6, 30.

Näkkilä J. ja Muranen, M. 2005. Alavalo tehostaa tomattituotantoa vähävaloisaan aikaan. Puutarha ja kauppa (painossa)

Rodriguez, B.P. ja Lambeth, V.N. 1975. Artificial lighting and spacing as photosynthetic and yield factors in winter greenhouse tomato culture. Journal of American Society of Horticultural Science 100:6, 694-697. 